\title{
No-one is unmusical: Elizabeth, everyday cheermongery, and active musical citizenship
}

\author{
Neil Thin
}

\begin{abstract}
Everyday cheermongers spread positive emotion through social contagion. This capability is illustrated here through a portrait of Elizabeth, a 'Suzuki method' violin teacher in Edinburgh. Through this example, we can learn about the important ways in which children and parents alike rely on skilled and dedicated felicitators to help them through the difficult balance between enjoyable and sociable music-making on the one hand, and the pursuit of musical excellence on the other. After presenting the philosophical and practical aspects of Shinichi Suzuki's 'everyone-is-talented' approach to instrumental music instruction, this paper argues for recognition of the key roles of music in facilitating happiness, and explores cultural variety in the promotion of musicality. While also recognizing that music education needs a democratic 'no child left behind' approach, the argument is that the full benefits of music are better realised through active musical engagement and social music-making. When not treated simply as an optional leisure activity or as a means to other ends, music can be a pathway to self-transcendent 'peak experiences' that can be achieved not only via the extraordinary performances of elite musicians, but also by savouring the very imperfect musical sounds produced by children.
\end{abstract}

Keywords: music, happiness, parenting, children, education, perfectionism, self-transcendence

\section{Introduction}

This paper argues for stronger recognition of music facilitators and music itself as sources of happiness. Focusing particularly on the joys of collective amateur music and on the tricky business of helping children and parents through the tribulations and delayed gratifications of early-stage instrument-learning, I present Elizabeth, a violin teacher, as an inspiring example of the 'everyday cheermonger', someone who spreads positive emotion through social contagion without consciously specialising in this function or advertising it as a professional service. Observation of music teachers who have this ability also offers us important lessons concerning the synergies and trade-offs among the various goods that music-making can provide. Elizabeth enables pupils and parents to enjoy progression towards better musical abilities without detracting from the joy of savouring every musical moment along the way. Her calm and supportive responses to children's mood swings teach children and parents how to cope with the inevitable stresses of learning difficult instruments. She spreads musical and social empathy through her facilitation of duets, jazz improvisations, and larger ensembles, and of parental and toddler participation. So unlike mere entertainers, Elizabeth's role goes beyond temporary mood-lifting. Those who witness her teaching feel more substantially elevated, persuaded to lead more exemplary and fulfilling lives than they otherwise would. 
Elizabeth has played a central role in the development of the 'Suzuki' approach to instrumental music instruction in Scotland. In portraying this approach, I also aim to link the understanding of music-making to broader themes of love, perfection, and self-transcendence. The arguments here about the importance of music for happiness, and about cultural variety in the promotion of musicality, can be extended in various ways to include other arts, leisure activities and therapies. I discuss several qualifiers to the common association of music and happiness: music education needs a democratic 'no child left behind' approach with a sensible balance between the momentary enjoyment of music as a process, and the longer-term pursuit of excellence; full benefits of music are best realised through active musical engagement and social music-making and music must be recognized as not just an optional leisure activity or means to other ends, but as a pathway to 'peak' or 'self-transcendent' experiences (also commonly called 'ineffable' or 'sublime' by music psychologists and philosophers).

Two further happiness-facilitation themes are broached here. Concerning upbringing in general, I want to emphasise that joy-spreading and music are fascinating capabilities for which we all have inborn talent. But these potentials are only realised if they are nurtured through good parenting, good schooling and a supportive cultural environment (Creech, 2010). Finally, the case study touches on a theme which has repeatedly cropped up in happiness scholarship and in lay theories of happiness: the importance of savouring ordinary everyday pleasures (Bryant and Veroff, 2007). When teachers like Elizabeth help children to enjoy music practice and to link it with other enjoyable activities, and when they persuade parents to enjoy the very imperfect musical sounds produced by children, and to enjoy the here and now rather than reducing childhood learning to the status of a pathway towards adult capabilities, they are teaching us how to savour. The western 'academic' or 'elite' classical music tradition has produced exquisite music but has also done a great deal of damage by scorning the more ordinary pleasures of simpler music and less polished musical performances.

\section{Grand twinkle}

Eleven children aged from 3 to 5 line the stage, all with home-made toy violins. Their teacher Elizabeth, a bundle of energy in her mid-70s, watches them in delight from the edge of the stage, and gestures to the pianist, who plays a chord. The children all bow, to rapturous applause, before Elizabeth herds them carefully towards the waiting arms of their moistcheeked grinning parents. Another line is quickly assembled, this one of slightly bigger children, all with real violins, some of which are improbably small - 1/32 size, little bigger than an adult hand. These little cherubs bow, then together with Elizabeth they play a rhythmic adaptation of Twinkle Twinkle, and bow again. And so on, via Swedish and Scottish folk tunes, blues, and Shostakovich sonatas, the informal but masterfully regimented concert continues for a couple of hours with an interval for juice and home-baked goodies.

It is in a school hall, but it is not a school event: it is a Sunday afternoon event co-organized by a few violin teachers and parents. No-one is forced to sit still for too long, and children's performances, though ritualised and neatly structured, are nonetheless smiley and informal. The youngsters listen to and enjoy a lot of the music, but are also allowed to get up and run around. Parents do not sit passively either: they are up on their feet chaperoning the young ones or preparing snacks. School concerts can be fun and informal too (and in Scotland they most definitely are more so now than they were a generation ago), but here the parents are active participants in their offspring's education. They are heavily involved: they have helped make the event happen, they know all the tunes, some have learned violin together with their children, and they have been co-responsible for their children's music practice. 
One or two of the children are stunning prodigies, playing difficult concerto and sonata excerpts beautifully at early ages. Less excellent musicians of variable abilities perform solo or in groups but with no noticeable reduction in commitment or in applause levels. Unlike the school concerts I remember from my youth, there is little sign here of anxiety about performance, or of reluctance among the performers. Partly, we can attribute this relaxed ambience to the supportive cultural ethos and social network, but a still more important clue is available by watching Elizabeth's body language. Whether sitting or standing as each child performs, and whether in a concert or in a lesson or group practice session, Elizabeth cannot help but give an unambiguously clear bodily display of involvement in the music, of empathy with the player, and of hedonistic savouring of every note.

If happiness is infectious, so is hunger. There are no limits to Elizabeth's appetite for the music that children play, and parents, too, seem to acquire an appetite for performances that can be deeply moving even when they are squeaky, out-of-tune, and rhythmically suspect. They are not alone in finding children's music-making uplifting: Placido Domingo, one of the greatest singers the world has ever heard, wept at a concert by the Venezuelan 'El Sistema' Youth Orchestra, saying they had evoked the strongest emotions he had ever felt (Gould, 2005); the cellist Pablo Casals wept "copiously" at a performance by 1,000 young Japanese pupils of Suzuki's violin school in 1961 (Suzuki, 1983: 101-2).

It is often hard to empathise with other people's sources of enjoyment. To some, music clubs and events like this one no doubt imply a heady mix of pushy parenting, unrealistic selfesteem promotion, and enforced merriment. I'm confident, though, that most parents get a strong and comforting sense of social and pedagogical progress from events like this. Doubtless many participants came reluctantly to today's event. In the run-up to the concert, children will have been wailing at being dragged away from their electronic nannies, parents stressed by the requirement to disrupt their Sunday routines by baking brownies and mending violins. But few are able to resist the compelling force of Elizabeth's organizational and motivational zeal, and once here they all enter happily into the spirit of the occasion. The iconic moment is when all the children and teachers, including the sonata and concerto players, join with the beginners in a 'Grand Twinkle' at the end. No doubt the beginners notice that this big rich sound that surrounds them and fills their bodies is a bit larger than their usual squeaks. But they also feel part of it, and they get a hopeful sense of where the squeaks might one day be heading. In the Grand Twinkle, they experience self-transcendence, to which we'll return later.

Have you ever allowed a piece of music to remove you gently from a foul mood and into a state of blissful calm or exhilaration? Have you felt similarly persuaded by a person whose mere presence, like beautiful music, seems effortlessly to invade those who come within their thrall, who seems to float above the troubles and indignities that cause so much anguish to the rest of us? What if the same person has the gift of spreading both music and joy? Elizabeth has no doubt always spread happiness, but since taking up the violin in her late 40s and becoming a teacher in her 50s, she has developed a genius for facilitating people's social and musical wellbeing.

\section{On social entrepreneurs and foot soldiers}

Teaching music is not my main purpose. I want to make good citizens, noble human beings. If a child hears fine music from the day of his birth, and learns to play it himself, he develops sensitivity, discipline, and endurance. He gets a beautiful heart. (Shinichi Suzuki, 1983: 105) 
Readers familiar with the 'Suzuki Method' of learning to play musical instruments will recognize that the above event follows the teachings of the Japanese violin teacher and 'Talent Education' promoter Shinichi Suzuki (Suzuki, 1983; Haugland, 2009). Inspired by a variety of western composers, musicians, philosophers, education theorists and scientists, Suzuki revolutionised music education in his native Japan and the social movement he inspired is a shining example of the benefits of multidirectional cultural globalization. His philosophy and practical instruction have inspired many thousands of teachers and musicians in North America and Western Europe and has been a crucial influence on the astonishing success of the Venezuelan 'El Sistema' youth music and social justice programme mentioned above (Gould, 2005). He is a classic example of a social entrepreneur who energetically promotes good simple ideas for human betterment through social transformation.

Not all witnesses of such Suzuki events describe them as benign sources of happiness. When first introduced to Europe in the 1970s, the Suzuki Method attracted expressions of concern about the semi-militaristic organization and 'Japanification' of music education. Like Montessori and Steiner schooling, it remains marginal to mainstream music education (in contrast to its more dominant role in North America). But Suzuki certainly qualifies for membership among the happiness promoters' of fame: his steadfast insistence on the importance of loving nurturance of young children's musical potential, his tireless promotion of parental involvement in musical education, and his recognition of the crucial lifelong strengths that adults can learn from observing the natural capabilities of children, have all been immensely important sources of wellbeing for thousands of people worldwide since the 1930s. Social movements rely on footsoldiers, though, not just on charismatic founders. So here I want to focus on the everyday niceness and loving energy that flows from one implementer of the Suzuki approach, Elizabeth, who has promoted the approach in Scotland since the 1970s. What is distinctive about 'everyday' cheermongers like her is that they spread good feelings and good happiness prospects unobtrusively and without fanfare or explicit happiness philosophy. They make no specific professional claim to happiness expertise. Whether through innate character, learned capabilities, or sheer willpower, they are exceptionally good at spreading happiness. They enhance the lives of those they interact with, both directly by making them feel good about themselves, but also over the longer term by helping other people find paths to lifelong happiness. It makes sense to acknowledge this, and to learn from their example. There are no doubt many millions of people worldwide who make exceptional contributions to the sum of human happiness in fairly direct and everyday ways not by producing grand plans or culture-defining new capabilities, but by helping people help themselves and others in various ways.

Suzuki's core assertions are that everyone has the potential to become 'talented', and that every child ought to be given the chance - with parental support, encouraging lessons, and a supportive cultural environment - to develop their innate musical abilities, just as they are given the chance to develop their ability to understand and speak a language. The fact that such assertions are regarded as noteworthy underlines the uncomfortable truth that while the virtue of universal schooling has caught on worldwide, there is a long way to go before the nurturing of musical capability is seen as a universal priority. The idea that everyone could and should learn to read and write developed thousands of years after the invention of literacy. It will take a little longer to get over the false belief that only a few people can be musical. 


\section{Music and happiness}

To introduce the concept of happiness into a conversation or into policy analysis is to ask questions about what our activities are for - what their value or importance is, what they mean to us, what joy they bring, whether that joy lasts and is compatible with other sources of wellbeing. Music is universally valued and the enjoyment of it is a fundamentally important innate capability, as researchers in the emerging field of evolutionary music psychology have been showing (Grinde, 2000; Peretz, 2006; Levitin, 2007; Sacks, 2008; Hodges \& Sebald, 2010). Yet its power and beauty are elusive and mysterious. So it is not surprising that discussion of music is linked with discussion of happiness and with the healing of social rifts and of individual minds and bodies. Plato argued that "music...gives a soul to the universe" and Shakespeare described it as the "food of love"; both recognized our astonishing ability and willingness to transcend ourselves through music. Even the notoriously miserable philosopher Schopenhauer admired music as the bath of the soul. ${ }^{1}$

Musicians and avid music listeners need no research evidence to convince them of the importance of music for personal happiness and social quality. Advocates of music therapy, music education, and community music have for decades been producing evidence in support of music, but most of this has been partisan, anecdotal, and lacking in scientific rigour (for a critical overview, and an outline of a scientific approach, see Skingley et al., 2011). While some recent scholarship treats the happiness benefits of music as akin to those of other 'leisure' activities (Hill and Argyle 1998), or as a kind of 'therapy' at personal level (Bunt, 1994; DarnleySmith \& Patey, 2003) or group level (Jenkyns et al., 2002; Pavlicevic, 2003; Oldfield, 2006), or as a temporary influence on emotions and moods (Kreutz \& Lotze, 2007), there is also a long tradition of more fundamental respect for music's role in the development of fulfilling lives and good societies. Like happiness, the forms and experiences of music can be exhilarating as well as calming; private or collective; active and deliberate or passive and unconscious; and they involve fleeting moments of exquisite pleasure as well as the lifelong musical narratives through which our engagement with culture and our private and collective identities are developed.

The aspects of musical experience that Elizabeth promotes most effectively are active and socially engaged musicianship - active musical citizenship, if you like. The difference between passive and active enjoyment of music is a bit like the difference between stimulating the brain's pleasure centres artificially with drugs, and doing so naturally through exercise or dance. As Roland Barthes put it, there are "two musics that are totally different arts: the music one listens to, and the music one plays" (1977: 149). Although most music therapy and education focuses on active musicianship, the rewards of listening (which can of course be conscious and in some senses active) are well researched (Menon \& Levitin, 2005). In Csikszentmihalyi's discussion of "the body in flow" he argues that although flow often arises from listening to music, "even greater rewards are open to those who learn to make music" (1990/2002: 111). Although at a personal level it is debatable whether the rewards of active music-making are necessarily 'greater' or just different, it is clear that playing music in groups entails both immediate and lifelong social benefits that are much more complex and significant than collective listening (Coffman, 2002). Music producers and the inventors of mp3 players can take a lot of credit for massively improving the ability of millions of people to listen to music. But if this detracts from active musicianship, then many of us will have lost something vitally important for our wellbeing and fulfilment.

\footnotetext{
${ }^{1}$ These quotes can be found in Plato The Republic, Shakespeare Twelfth Night, respectively.
} 
The Suzuki Method encourages both passive and active musicianship from the earliest stages of life. Families are reminded of the importance of a supportive musical environment in which children learn to enjoy and remember a variety of kinds of music. And the democratic insistence on everyone's potential to become good active musicians serves as a powerful antidote to those who assume that only an elite minority should play musical instruments. Numerous studies have confirmed that in music, as in many other specialised capabilities, it takes ten thousand hours of practice (e.g. 3 hours a week over a decade) to become a worldclass expert (Levitin, 2007: 193), but on a small fraction of that you can become really good, and a time investment comparable to tooth-brushing and having a shower is all it takes to get some sense of the joys of active music-making. But in any case, 'investment' is misleading: most of the fun is in the process, not the final achievements.

\section{Music clubs and social capital}

Robert Putnam's image of "bowling alone" (2000) is now well known as a metaphor representing the decline of informal social engagement in the USA. Music is rather more varied and versatile than bowling, and you can actually spend a lifetime deriving intense enjoyment from playing or listening to music alone. When necessary, fellow players and audiences can simply be imagined. But most musicians would agree that participation in musical ensembles, and performing to audiences, provide some of the most rewarding and deeply-felt sources of fulfilment in their lives. The economistic and instrumentalist metaphor of 'social capital' is woefully inadequate to describe the value of musical participation, but it is also true that music plays crucial functions in many of the most valued forms of associational life worldwide. Unsurprisingly, not long after scholars and policy-makers began taking an interest in social capital during the 1990s, a steady stream of interest in music-making and social capital followed (Dowling 2008; Langston \& Barrett, 2008)

Elizabeth's weekly fiddle club involves a small cross-section of the children who played in the above concert. Here they play a mix of jazz, folk, and classical pieces. Sometimes the club makes excursions to a local old people's home or goes busking on the Royal Mile during the Edinburgh Festival. Here again, people often have to be prodded into participation, and it is rarely stress-free. But if asked to evaluate the importance and value of the club, parents and children alike will be unequivocal in their gratitude to Elizabeth for making it happen. They know they've been dragged into a collective self-help system that often intrudes on other parts of their lives, but which they wouldn't want to do without.

Elizabeth is impressive in her ability to organize large-scale concerts and workshops with cheerful informality, but it is in her smaller-scale engagement with fiddle club that her exceptional capabilities are most evident. Every child and every parent knows that they will get some of her attention at fiddle club, and that Elizabeth will notice and feel their absence when they miss a week. Just as they sense her involvement in their music when they're playing, they sense that their participation in the events she organizes matters to her in an intensely personal way. It's not that she needs them to make up the numbers or that she feels that one class missed is a delay on their path to excellence: it's simply that she seems to feel the intrinsic value of everyone she encounters more keenly and more democratically than most of us do.

In his blockbuster bestseller How to Win Friends and Influence People, Dale Carnegie reminded readers that whereas most of us try hard to get others to like or admire us, or be influenced by us, a few exceptional individuals achieve much better results simply by showing a genuine loving interest in other people. This describes Elizabeth perfectly, and I'm sure Carnegie would have been the first to admit that people like her don't need to read self-help literature. 


\section{On talent, effort, love, and self-transcendence}

The keystone of Suzuki's musical pedagogy is that "talent is not inherited" but must, like language, be nurtured from birth by loving parents and by a supportive cultural environment (Suzuki, 1983: 9). His hunches have since then been supported by a mass of research that has comprehensively demolished the common myth that musical 'talent' is some kind of inborn genius, possessed by a few individuals, that simply expresses itself effortlessly. In reality, many thousands of hours of hard practice are the main factor in the production of musical excellence (Sloboda, 2005, chs. 15 \& 16; Levitin 2007, ch. 7), but to persuade children to spend even a fraction of that time practising requires teacher and parent motivators who facilitate what the psychologist Carol Dweck has called a "growth mindset" (Dweck, 2006, especially ch. 7).

All cultures value music highly, but in some cultures - especially literate and stratified ones - active musicianship is marginalised to a small minority of specialists who are labelled as genetically destined to this occupation and/or capability. Even in contemporary western societies, where music pervades almost every aspect of our everyday experiences and almost limitless musical choice is available to all, for most people music remains largely a passive listening experience, and many schools offer pitifully inadequate opportunities for children to learn to play music or even sing.

If we agree with most musical educators that the capability of active musicianship should be democratized, the question then arises as to whether the objective is to aim for ultimate excellence or to emphasize the enjoyment of the process, including those thousands of hours spent practising. To learn a musical instrument you need to get used to delaying gratification, promising yourself that things will go better for you in the long run. This can be approached masochistically as a form of long-term self-mortification, or more positively you can turn the pains and frustrations of practice into a process of 'flow', in which endless repetitions and infinitesimal signs of progress become a source of absorption and fascination. You need a balance between recognizing nasty sounds that you can do something about, and hearing or at least imagining better sounds that might eventually come under your control. You also need a balance between effort and gratification: if you can enjoy the imperfect sounds you make while practising, this is good so long as this enjoyment doesn't amount to lazy satisfaction that stops you from trying to improve.

Playing with others can help you through this process, giving you a positive aural illusion of sounding much better than you are, while also showing you a bigger and better sound to aim for. It is amazing how good a sound can come out of ten beginners playing together. According to the music philosopher Jeanette Bicknell, music moves us primarily because all kinds of musical engagement, even solitary listening, are intrinsically social: music gives us compelling reminders of our need for attachment to others (2009: viii). Perhaps this is why, when people describe moments of extreme passion in musical listening, they tend to refer to puzzling combinations of pleasure and anguish or pain, a 'poignancy' which as Jerrold Levinson (2004) has argued reflects the bittersweetness of life itself. You experience momentarily the unbelievable beauty of passionate union with Beethoven's soul, yet at the same time he was some weird grumpy guy who died in Germany a long time ago and the people playing his music to you are very uncool people in penguin suits. The feeling of empathy with composers is extremely powerful yet often deeply puzzling (Putman, 1994). The combination of psychotropic rhythms and crowds is a heady mixture leading to unforgettable and seemingly magical altered states of consciousness (Sylvan 2005; Ehrenreich 2006; Aldridge \& Fachner, 2009). More mundanely, if you're going to play music with other people, you also need to learn that social participation often means expanding your interests demographically 
and spatially as well as temporally. You need to do things that appear to be largely dutiful and altruistic rather than self-interested, and you need to develop musical empathy with fellow players (Schögler \& Trevarthen, 2007; Laurence 2008).

For many of us, these important ways of stretching or moving the self across time and into larger social wholes don't come easily. Without felicitators like Elizabeth we'd be a lot less good at it. Other people can be hell. Not only can they ruin our musical fun by making the wrong musical noises, but they can be downright antisocial even in the presence of a good facilitator. Elizabeth doesn't ignore a misbehaving child, but neither does she draw attention to misbehaviour. When forced to reprimand children she achieves what few parents can achieve, quickly persuading the child that there are more interesting and fun things to do than cause trouble. Educational theorists may advise us to reprimand and punish the behaviour and not the child, yet for Elizabeth it comes naturally to brush bad behaviour gently aside with no hint of anger, hatred, or moral outrage. Parents attending her lessons and group practices get free instruction in good parenting, and several have agreed with me that they often find themselves, when in the midst of family traumas, asking themselves 'what would Elizabeth do?' We can only learn so much from parenting manuals, and in these socially fragmented days the opportunity to learn social skills like this first-hand is gold dust.

The violin is not the most obvious choice of instrument for three-year-olds to take up. More biddable instruments such as recorders, ukuleles and pianos give young children at least some instant gratification. Nowadays computers, electronic keyboards, soundbeam technology, and programs like 'sing star' on PlayStation provide ample opportunities for giving children an immediate sense of musical power. By contrast, the violin stubbornly holds out for months or years before rewarding the beginner with something that sounds like music. Elizabeth, now in her mid-seventies and a good amateur violinist herself, knows that her main gift is in helping children and parents through the difficult early years. She passes pupils on to other teachers when they begin to need intense technical instruction. But by that stage most of her pupils have developed a sustainable love of all aspects of music: they enjoy their lessons, their practice time, performing solos, performing in groups, and playing together informally in fiddle club sessions.

There is a fascinating consistency between Elizabeth's unconscious instruction in how to deal with troublesome behaviour, and her conscious instruction to children in how to get through the potential nightmare of a difficult practice session. Just as parents quickly become infuriated with misbehaviour, children quickly become livid when their fingers and instruments refuse to express the sounds they were hoping to hear. Elizabeth, like all good music teachers, has a raft of tricks for helping children get through the tantrums that music practice inevitably provokes. If their fingers misbehave by playing the wrong notes, or their bows misbehave by going squint and scratching, you don't ignore it but you don't dwell on it as if it were a moral outrage. It's to be expected, and when it happens repeatedly it's time to get those fingers and bows to do something more fun, such as playing with finger puppets or 'hunt the bow', before returning to more serious practice afterwards. Children learn to treat their fingers and instruments lovingly and with a good mixture of discipline and indulgence.

What is produced by Elizabeth and through the events and processes she facilitates is not limited to musical capabilities, important though they are. It includes also a wide range of abilities and dispositions that are perhaps best summarized by the concept of love. To progress in music, you must learn to make long-term commitments to your instrument that are quite distinct from the instant gratifications of making any noise by banging a drum or crashing a cymbal. Attachment to the instrument develops over a long period and requires recognition 
that your relationship with it will at times be problematic. Just as the concept of romantic love is often expressed as a feeling of self-transcendence, of being at one with the lover, so musicians describe their relationship with their instruments and with music in terms of life-long passions that dissolve and extend the self into something more profound or ineffable than could be included within a bounded self.

Like happiness, love is an important value in all cultures, though widely variable in the way in which it is treated. Whether the expected objects of love are actual or potential partners, kin, friends, society in general, activities, or the natural environment, love is often conceived of as a force external to ourselves over which we have little or no control. Similar attitudes to happiness have been common throughout history and around the world. But as we learn to anticipate and promote happiness, we can and must also learn to nurture love. Our inborn dispositions and abilities to love are, like our felicific dispositions, highly variable; but they can also be cultivated through individual and collective effort. As the ethnomusicologist Blacking long ago observed, music tends to play crucial roles in preparing humans for the "hard task" of loving other people (1973: 103); it does so, I would argue, by opening us up to selftranscendence, making us not only recognize but also enjoy the fact that we are a lot less individual than we sometimes imagine ourselves to be.

Self-transcendence is commonly recognized by psychologists and therapists, and religious leaders, as being essential for both wellbeing and virtue, an essential complement to selfconcern and self-enhancement (Meulemann, 2009). But if you have browsed through some of the copious literature on self-transcendence that has emerged since Viktor Frankl's 1966 essay on it, you can't help but have noticed that most of it focuses on transcending selves that are exceptionally problematic due to moribundity, illness or emotional dysfunction. You could be forgiven for thinking that unless you are dying, ill, or mad you don't need to bother with selftranscendence. Self-transcendence is a crucial capability for all of us, not just a therapy for exceptionally vulnerable or damaged selves.

Self-transcendence can be about escaping the confines of the everyday self and its associated identities and roles. But it can also, more positively, be about a sense of harmony or union with other people, with our previous or future selves, and with broader nonsocial environments. More radically, we could also question the notion that there is, by default, a coherent and relatively isolated self that can be 'transcended' - and this kind of radical questioning is encouraged, if only temporarily, by mystical experiences such as trance states, communion with nature, and passionate involvement in music. As many anthropologists have shown, belief in a discrete, integral self may be dominant in western cultures but much less, or not at all, dominant in nonwestern cultures (Christopher, 1999). Baumeister (1991) considers music as one among many techniques we must sometimes use for escaping the "burden of the self" (other such escapes include alcohol, dance, and meditation), yet his metaphor of escapism perhaps wrongly presupposes an entity from which we can escape. A better metaphor might be that of tuning in to a different kind of conversation in our heads, a less egotistical and perhaps less analytical and more holistic and fluid one. Self-transcendence is an elusive concept. It is about 'going beyond' normal everyday self-concepts and normal coherence, and experiencing feelings and thoughts that free us from narrow self-concern and self-interest.

The study of music in action, whether solo or ensemble, practice or performance, reveals uniquely human ways in which our souls or identities are inescapably informed and inscribed by other people - listeners, composers from the past, fellow players. Much of the magic that music works, both immediately and over a lifetime, seems to have something to do with our transcendental existence, or 'self-transcendence' if you must imagine a core being to be 
transcended. For those who have invested perhaps unrealistically in particular versions of the self, such as the concept of a uniquely admired discrete entity, musical engagement is a vitally important and humbling experience. If listening to profoundly moving music is a bit like gazing at the firmament in a clear night sky, being moved while playing is like being a stargazer, star-mover, and star at the same time. Musicianship gives us crucial opportunities to feel an ineffable sense of creative fusion with wider social and nonhuman universes.

At a simple, concrete level, Elizabeth's evident propensity to engage with other people and with music-making illustrates clearly the self-transcending value of musical citizenship. Whereas an elitist teacher might enjoy their star pupil's performance largely with a view to boosting their own ego and that of their pupil (and hence their disparagement and discouragement of more ordinary pupils), Elizabeth enjoys and reveals the beauty of democratic musicality. Pupils may try to emulate her playing and her enjoyment of music, but they aren't trying to produce in themselves a carbon copy of magisterial excellence. They recognize that through musical participation they become part of a much more important wider whole.

But although Elizabeth's example illustrates the 'social' nature of music, I think we should pause before accepting at face value Bicknell's assertion that "music and the experience of music are fundamentally social, rather than strictly personal or individual" (2009: 89, my emphasis). Bicknell argues most persuasively that the musical self is a social one, yet seems unable to shake off entirely the metaphor of a socially isolated, pre-social self, a separate person who then engages socially through music. Though some of us act out this illusion more than others, and some are more troubled by the vulnerability of the self than others, there is no escaping the fact that our selves are 'social' from before we were born. For example, hearing music while in the womb is an important form of prenatal socialization. I agree with Bicknell (2009: viii) that music's significance lies in its "elemental social character": there is fascinating overlap and synergy between the experiences of absorption in music and absorption in society. But I wonder in what sense she thinks this is different from a 'personal' conception of musical enjoyment. As Daniel Goleman's synthesis of recent research on 'social intelligence' has amply demonstrated, we are "wired to connect" with other people, and we do so, for example musically, using our mirror neurons (Goleman, 2007: 13). Now that research on mirror neurons has shown that other people - in the form of our subconscious reflections of their emotional states - are in a rather literal and biological sense inside our heads, the idea of a non-social isolated self is hard to sustain.

When you watch someone who expresses musical social engagement as clearly as Elizabeth does, you can't help but recognize the artificiality of our distinction between 'individual' and 'society'. Nor can you help but wonder whether failure to recognize this artificiality is perhaps at the root of a great deal of human unhappiness. If music does help us to escape the self, this is perhaps because it enables us to feel our total absorption in society even if we find this very hard to think. Strangely, music is also often said to help us escape society, when for example we hide away in a musical bubble using headphones to screen off the outside world (Sloboda, 1999). What seems to happen is that we use music to drown out either troublesome inner chatter or external chatter, or both. And if the absorption we achieve through active rather than passive musical engagement is that much more total, so much the better.

I've asked other parents of Elizabeth's pupils what they understand as the core of the magic that she works with children and parents alike. Often, they have referred to the boundless love she seems to feel for everyone who enters her ambit, and her loving commitment not only to pupils but also to the tiniest detail of her every activity. Love, like happiness, is both an 
experience and a character trait. Perhaps more than any other human experience or virtue, love reminds us of the everyday importance of self-transcendence. Both love and music tend to involve bittersweet poignancy, and it seems no accident that love tends to be expressed musically or that music tends to experienced as a peculiarly ineffable and transcendent kind of love (Hodges, 1996: 36). Happiness and love are related but different, and if there are other goods that can rank alongside happiness as 'ultimate' values, love must surely be among them.

\section{Enjoyment, excellence, and learning to savour normality}

Recently, pushy parenting has again loomed large in public debate with the publication of the Yale law professor Amy Chua's Battle Hymn of the Tiger Mother (2011). In this wilfully controversial autobiography, which makes no attempt to engage with many decades-worth of serious scholarship on the adverse life outcomes of authoritarian parenting and perfectionist instruction, Chua tells of her relentless hyperparenting project that drove her two daughters to academic and musical 'success' via Chua's interpretation of the 'Suzuki' method. This entailed getting her daughters to practice several hours a day from the age of three and denying them nearly all the social joys and relaxations of normal childhood.

As every kind of educator knows, bringing up children involves seemingly irreconcilable trade-offs between enjoyment and excellence, between the ordinary masses and the ultratalented elite, and between present fun and future capabilities. And if you have a lot of children in your charge, it is never easy to promote simultaneously the ordinary flourishing of the majority and the extraordinary capabilities of the exceptionally quick learners. Inevitably, some individuals and some institutions either take the elitist path of favouring and promoting exceptional excellence, while others go for common enjoyment of the masses at the expense of excellence. If educational success is measured by the exceptional achievements of the gifted few, at least some of the aspects of the wellbeing of the masses must be damaged as they become second-rate witnesses to the elite's pursuit of excellence.

The same trade-offs also map onto trade-offs between childhood and adulthood, and between educational processes and educational outcomes: if excellence is the privileged objective, schooling is reduced to a means by which deferred benefits are to be achieved, whereas if the joy of learning is privileged then at least some of the anticipation of future excellence must be foregone in the interest of a happy childhood.

Elizabeth's biography is instructive in this regard. She grew up in the profoundly elitist musical tradition that prevailed in posh Edinburgh schools until recently. Music was mainly focused on a select few 'musical' people, usually from 'musical' families, playing almost entirely the elite repertoire of a few musical geniuses in the western 'classical' (or 'academic', or 'high art') tradition. The masses were meant to appreciate, but not participate except passively as consumers. After just a year of learning the violin at school, Elizabeth, like perhaps a majority of instrumental beginners in those days, was told that there was little point in continuing as she lacked talent and had no prospect of becoming an excellent violinist. 25 years later little seemed to have changed in the Edinburgh classical music tradition: her son returned from one of his violin lessons to say that after he'd played through the piece he'd practiced all week, his teacher had slumped onto the piano and wept at his incompetence. By then in her late forties, Elizabeth responded by buying herself a violin and teaching herself. Within a few years, she had introduced the Suzuki method to Scotland and was helping several thousands of individuals grow up to enjoy playing and listening to music from a wide variety of musical traditions, and to participate in a vibrant social network. 
I would argue that the Suzuki approach to music education provides substantial reconciliation of these trade-offs, but that this effect relies very strongly not only on the inspirational philosophy of the movement's charismatic founder, but on the character and sheer effort of practitioners like Elizabeth. All too often, music teachers succumb to the temptation to focus most of their efforts on the long-term and selective grooming of a few exceptionally gifted musicians. The results are often breathtakingly beautiful musicianship that contributes to the most stunning achievements of humanity. But the human cost in this production process may include untold miseries for the vast bulk of children who learn to despise their own modest musical capabilities, and who end up seeing the whole process of learning and practising as a waste of time if it doesn't lead to exceptional excellence.

When Csikszentmihalyi interviewed musicians, he found many whose enjoyment of music had clearly been badly spoiled by the perfectionism of their teachers and parents (1990/2002: 112). Many parents quite correctly entertain ethical doubts about making children perform musical solos. Musical biography studies in the United Kingdom have shown that happy memories of childhood musical performance are rare, and massively outnumbered by painful memories which frequently put children off active musicianship for life (Sloboda, 2005: 186). Levitin argues that contemporary Western society has seen a widening of the 'performance chasm' that separates the musical elite minority from the masses who gave up all musical ambition in childhood. Western musical culture, he argues, is uniquely discouraging to all but the experts: not only is musical amateurism more disparaged in the West than are other kinds of amateurism (such as cooking or sport), but other cultures don't suffer the same obsession with extremes of excellence to the detriment of more modest capability registers (2007: 194).

I share Levitin's worries about elitism, but I doubt whether trends are quite as bad as he portrays. For example, Elizabeth's approach to musical education is in Scotland far less exceptional today than would have been the case in the 1960s. In contrast to the elitist music teachers who discouraged her in the 1950s and her son in the 1970s, she encourages children and parents to enjoy and savour music at all levels of capability, while also teaching children that hard work can lead to deferred rewards too. An ethnographic study of active amateur musicianship in Milton Keynes in the early 1980s found a wide diversity of highly committed musicianship, much of it based on self-instruction and self-discipline as well a community support (Finnegan, 1989). This nonperfectionist approach to music sounds similar to what Margaret Mead said was normal in Bali in the 1930s, where everyone gets to take part and every man is at least at some key ritual moments a kind of musical 'professional': when villagers watch young people doing a show "the interest ... fastens not on the final performance, as it does in America ... but on the rehearsals" (Mead, 1941; cited in Merriam, 1964: 160).

Despite her earlier maltreatment by the musical aristocracy, Elizabeth is not driven by any compensatory demophilic dogma or cult of mediocrity. She adores musical excellence and glows with pride when her pupils, as some inevitably do, progress quickly to extraordinary ability at an early age. It's just that she genuinely enjoys and savours, just as much, the more ordinary capabilities of the rest. She gives all of them strong encouragement to strive for ever better capabilities, but also, perhaps more inconspicuously, encourages them to enjoy whatever they can do at every stage along the way. Her pupils can have their cake and eat it (and by the way it isn't at all uncommon for her pupils to come away from her lessons literally with crumbs on their lips, having mixed the pleasures of music with the enjoyment of snack time). 


\section{Conclusions: on music, social progress, and life enhancement}

I opened by arguing that participation in the musical events that Elizabeth organizes gives a pleasing sense of social progress. Democratizing the business of music-making, and doing so in child-friendly and parent-friendly ways which enhance the social experiences of music-makers, seem to me to be extremely important ways in which societies can progress. Plato recognized this at the level of individual pedagogy but his thinking on the social benefits of music never led to a strong tradition in studying and celebrating the role of music in facilitating good lives and good societies. Although there have been occasional attempts to discuss links between music and social progress (Frith, 2007; Allen, 1946), most writing linking music with progress is either about individual progress towards musical excellence, or else takes the form of obscure and irresolvable aesthetic and philosophical debates about the artistic, literary, and sonic qualities of musical compositions and performances. Music certainly does have ineffable intrinsic value that can't be reduced to its psychological or sociological uses, but the extrinsic values of music need to be understood and celebrated too.

Looking at Elizabeth, particularly in her capacity as an exponent of the Suzuki approach to music education and parenting, has given us opportunities to recognize a number of important cultural themes in happiness studies that would certainly merit more careful attention. First, the ability to facilitate happiness is an important life skill that combines character traits with hard altruistic work. Though highly valued when we bother to pay attention to it, the social function of the cheermonger is not often highly rewarded with money or status. Nor is it necessarily focused explicitly on the production of happiness. Elizabeth has never, to my knowledge, tried to justify her work in the name of happiness. She simply believes passionately in the various activities that she promotes - active musicianship, cooperative play, early learning with supportive parental involvement, noncompetitive pursuit of excellence, and social engagement. We could call cheermongery 'emotional labour', a term coined by the Marxist-feminist sociologist Arlie Hochschild with reference to the mood management of air hostesses (Hochschild, 1983). I agree with Hochschild that the value of this work needs more recognition, but unlike her I don't want to look at it primarily in terms of exploitation and pathology: when emotion work (let's at least give it a more morally neutral label) is done well and willingly it is a beauty to behold, and there is no doubt that exponents like Elizabeth take great pride and joy in their emotional contribution to society.

Second, like many other skills, those we have looked at (musicianship, good parenting, prosocial behaviour, enjoyment of work, deferred gratification, etc) are 'inborn' in all of us but nonetheless don't just 'come naturally': they need to be cultivated, and they require cultural support for their expression. We need educational systems (and of course not just schools but communities, social networks, and value systems) that cultivate and celebrate the full variety of capabilities that everyone is born with the potential to develop.

Third, musical abilities - practising, anticipating improvement while enjoying the moment, making music, performing individually and collectively, listening - are some of the life skills that are most crucial for happiness, and yet these tend in many cultural contexts to be inadequately nurtured. All cultures recognize the value of music, some (e.g. youth cultures) perhaps more than others. But music tends to sit awkwardly with other values and its power is not always seen as an unmixed blessing. Those who play music, or create it, teach it, or otherwise facilitate it, are not always the culture heroes we might expect them to be. Active music-making and composition are often seen as ultra-specialist activities best left to a tiny gifted and/or marginal and even deviant minority, and often based on elitist and/or authoritarian, creativity-inhibiting instruction (Merriam, 1964; chs. 7 \& 8). Many schools 
worldwide make little or no attempt to nurture musical abilities, and those that do often fail due to the neglect of the importance of early learning. Even in Western schools, where there is nearly always some kind of musical instruction albeit mainly focused on listening and discussing rather than playing, it is still often not effectively mainstreamed within the curriculum, nor incentivised with public recognition, nor properly evaluated. Instead it is seen as an optional activity like sport or religion.

Finally, goods whose value is not adequately theorised and measured, or whose absence is not necessarily perceived immediately as catastrophic, tend to be taken for granted. We all know, surely, how much we collectively rely on the goodwill and energy of cheermongers like Elizabeth. They keep us sane, they spread good feelings contagiously through social networks, they foster peace and love, they inhibit our tendencies to get angry and upset over petty quarrels and temporary setbacks. But we rarely think about happiness promotion as a critically important social function that could be better incentivised and celebrated. Music promotion is similarly undervalued and undernourished not because we don't value music, but because we can't see it as a critically important component in social processes and in cultural achievements which vary widely from one culture to another, or from one family or school to another, depending on how well they are nourished.

Two of the key insights from positive psychology are that we can derive a great deal of happiness through the expression of thanks, and from the regular habit of savouring the good things in life (Bryant \& Veroff, 2007; Emmons 2007). To promote my own happiness, I would like to offer thanks to Elizabeth, while savouring and promoting recognition of her extraordinary gift for joy-spreading. Just as the sublime qualities of music can't be captured in words, so the ineffable niceness of a person can only be indirectly apprehended by watching their actions and relationships. We can nonetheless learn a lot more about music, and about everyday niceness, by doing our best to work out how everyday cheermongers work their magic.

\section{Author}

Neil Thin

University of Edinburgh

n.thin@ed.ac.uk

Publishing Timeline

Received 31 January 2011

Accepted 5 April 2011

Published 20 July 2011

\section{References}

Aldridge, David, and Jörg Fachner [eds], 2009, Music and Altered States: Consciousness, Transcendence, Therapy and Addictions. London: Jessica Kingsley.

Allen, Warren D., 1946, 'Music and the idea of progress', Journal of Aesthetics and Art Criticism 4(3): 166180. http://dx.doi.org/10.2307/427002

Barthes, Roland, 1977, 'Musica practica', In Image, Music, Text: Essays selected and translated by Stephen Heath. New York: Hill \& Wang, pp. 149-154.

Baumeister, Roy F., 1991, Escaping the Self: Alcoholism, Spirituality, Masochism, and Other Flights from the Burden of Self. New York: Basic Books.

Bicknell, Jeanette, 2009, Why Music Moves Us. Houndmills: Palgrave Macmillan.

Blacking, John, 1973, How Musical Is Man? London: Faber.

Bryant, Fred, and Jean Veroff, 2007, Savoring: A New Model of Positive Experience. New Jersey: Erlbaum. 
Bunt, Leslie, 1994, Music Therapy: An Art Beyond Words. London: Routledge.

Christopher, John C., 1999, 'Situating psychological well-being: exploring the cultural roots of its theory and research.' Journal of Counseling and Development 77(2): 141-152.

Chua, Amy, 2011, The Battle Hymn of the Tiger Mother. Harmondsworth: Penguin.

Coffman, Don D., 2002, 'Music and quality of life in older adults', Psychomusicology 8(1-2): 76-88.

Creech, Andrea, 2010, 'Learning a musical instrument: The case for parental support', Music Education Research 12(1): 13-32. http://dx.doi.org/10.1080/14613800903569237

Csikszentmihalyi, Mihaly, 1990/2002, Flow. [2nd Edition]. London: Rider.

Darnley-Smith, Rachel, and Helen M. Patey, 2003, Music Therapy. London: Sage.

Dowling, Martin , 2008, 'Fiddling for outcomes: Traditional music, social capital, and arts policy in Northern Ireland', International Journal of Cultural Policy 14,2:179-194. http://dx.doi.org/10.1080/10286630802106359

Dweck, Carol S., 2006, Mindset: The New Psychology of Success. New York: Random House.

Ehrenreich, Barbara, 2006, Dancing in the Streets: A History of Collective Joy. Cambridge: Granta.

Emmons, Robert, 2007, Thanks!: How the New Science of Gratitude Can Make You Happier. New York: Houghton Mifflin.

Finnegan, Ruth, 1989, Hidden Musicians: Music-making in an English Town. Cambridge, UK: Cambridge University Press.

Frankl, Viktor, 1966, 'Self-transcendence as a human phenomenon', Journal of Humanistic Psychology 6: 97106. http://dx.doi.org/10.1177/002216786600600201

Frith, Simon, 2007, 'Can music progress?: Reflections on the history of popular music', Musicology 7: 247257.

Goleman, Daniel, 2007, Social Intelligence: The New Science of Human Relationships. London: Arrow Books

Gould, Jens Erik, 2005, 'Venezuela youths transformed by music'. http://news.bbc.co.uk/1/hi/world/americas/4457278.stm

Grinde, Bjørn, 2000, 'A biological perspective on musical appreciation', Nordic Journal of Music Therapy 9(2): 18-27. http://dx.doi.org/10.1080/08098130009477997

Haugland, Susan L., 2009, 'Suzuki's mother tongue method and its impact on strings in music education in the United States', American String Teacher 59(2): 28-31.

Hills, Peter, and Michael Argyle, 1998, 'Positive moods derived from leisure and their relationship to happiness and personality', Personality and Individual Differences 25(3): 523-535. http://dx.doi.org/10.1016/S0191-8869(98)00082-8

Hochschild, Arlie R. 1983, The Managed Heart: Commercialization of Human Feeling, Berkeley: University of California Press.

Hodges, Donald E. [ed], 1996, 'Human musicality'. In D. E. Hodges [ed], Handbook of Music Psychology [2nd Edition]. San Antonio, Texas: IMR Press, pp. 29-68.

Hodges, Donald E., and David Sebald, 2010, Music in the Human Experience: An Introduction to Music Psychology. London: Routledge.

Jenkyns, Marian, Alison Davies, and Eleanor Richards [eds], 2002, Music Therapy and Group Work: Sound Company. London: Jessica Kingsley.

Kreutz, Gunter, and Martin Lotze, 2007, 'Neuroscience of music and emotion', In W. Gruhn and F. Rauscher [eds], Neurosciences in Music Pedagogy. New York: Nova Science, pp. 143-167.

Langston, Thomas W., and Margaret S. Barrett, 2008, 'Capitalizing on community music: A case study of the manifestation of social capital in a community choir', Research Studies in Music Education 30(2): 118-138. http://dx.doi.org/10.1177/1321103X08097503

Laurence, Felicity, 2008, 'Music and empathy'. In O. Urbain [ed], Music and Conflict Transformation Harmonies and Dissonances in Geopolitics. London: I. B. Tauris \& Co, pp.13-25.

Levinson, Jerrold, 2004, 'Musical chills and other musical delights'. In J. Davidson [ed], The Musical Practitioner. Aldershot: Ashgate, pp. 335-351.

Levitin, Daniel, 2007, This is Your Brain on Music. London: Atlantic Books.

Mead, Margaret, 1941, 'Community drama-Bali and America', American Scholar 11: 79-88. 
Menon, V. and D.J. Levitin, 2005, ‘The rewards of music listening: Response and physiological connectivity of the mesolimbic system', NeuroImage 28(1): 175-184. http://dx.doi.org/10.1016/j.neuroimage.2005.05.053

Merriam, Alan P., 1964, The Anthropology of Music. Evanston, IL: Northwestern University Press.

Meulemann, Heiner, 2009, 'Self-concern, self-transcendence, and well-being', European Sociological Review 26(4): 385-399. http://dx.doi.org/10.1093/esr/jcp027

Oldfield, Amelia, 2006, Interactive Music Therapy: A Positive Approach: Music Therapy at a Child Development Centre. London: Jessica Kingsley.

Pavlicevic, Mercedes, 2003, Groups in Music: Strategies from Music Therapy. London: Jessica Kingsley.

Peretz, Isabelle, 2006, 'The nature of music from a biological perspective', Cognition 100(1): 1-32 [Special issue: The Nature of Music]. http://dx.doi.org/10.1016/j.cognition.2005.11.004

Putman, Daniel, 1994, 'Music and empathy', Journal of Aesthetic Education 28(2): 98-102. http://dx.doi.org/10.2307/3333275

Putnam, Robert J., 2000, Bowling Alone; the Collapse and Revival of American Community. New York, London: Simon \& Schuster.

Sacks, Oliver, 2008, Musicophilia: Tales of Music and the Brain. London: Picador.

Schögler, Ben, and Colwyn Trevarthen, 2007, 'To sing and dance together: from infants to jazz'. In S.Braten [ed], On Being Moved: From Mirror Neurons to Empathy. Amsterdam: John Benjamins Co, pp. 281-302.

Skingley, Ann, Stephen M Clift, Simon P Coulton, and John Rodriguez, 2011, 'The effectiveness and costeffectiveness of a participative community singing programme as a health promotion initiative for older people: protocol for a randomised controlled trial', BMC Public Health 11.

Sloboda, John, 1999, 'Everyday uses of music listening: a preliminary survey'. In Suk Won Yi [ed] Music, Mind, and Science. Seoul: Seoul National University Press, pp. 354-5.

Sloboda, John, 2005, Exploring the Musical Mind: Cognition, Emotion, Ability, Function. Oxford and New York: Oxford University Press.

Suzuki, Shinichi, 1983, Nurtured by Love: The Classic Approach to Talent Education [Trans: Waltraud Suzuki]. Miami: Suzuki Method International.

Sylvan, Robin, 2005, Trance Formation: the Spiritual and Religious Dimensions of Global Rave Culture. New York/London: Routledge. 